\title{
Global Relevance of Translational Research in Engineering and Project Management
}

\author{
Kriengsak Panuwatwanich \\ Editor \\ Editorial \\ Available online July 11, 2016
}

In this issue of the EPPM journal, we include five interesting papers reporting on the research undertaken within the contexts of five different countries: Italy, Norway, Saudi Arabia, Romania and Iran. These papers address various key issues in engineering and project management, including green building rating system, agile project management, construction delays, awarding process of public construction projects and Building Information Modelling (BIM). A good mixture of both quantitative and qualitative research methods is also worth noting in this issue.

The first paper in this issue is an extended version of the Excellent Paper awarded at the EPPM2015 conference in Gold Coast, Australia. In this paper, M.R. Hosseini, E. Azari, L. Tivendale, S. Banihashemi and N. Chileshe explore barriers and drivers associated with the adoption of BIM in the Iranian Construction Industry. The authors reveal that the most important barriers are linked with the nature and structure of the Iranian Construction Industry and its business environment, while the drivers stem from monetary gain and improved competitiveness. The authors conclude that the supportive regulatory and financial environment by the policy makers is required to drive the adoption of BIM in Iran. Similar findings are also identified elsewhere (e.g. Panuwatwanich and Peansupap, 2013).

The second paper by N.O. Alotaibi, M. Sutrisna, and H.Y. Chong examines factors causing delays in public construction projects in Saudi Arabia. The authors identify top factors causing delays such as inadequate skills and qualifications of workers and an overemphasis on the lowest bidder when awarding a contract. The authors then map out the process and project management tools and techniques required to address these factors. The authors finally propose guidelines that could be adopted to help practitioners minimise construction delays in Saudi public projects.

Also focusing on public projects, the third paper by M.V. Patras and C.S. Banacu examines the awarding process of Romanian public procurement contracts. Using a qualitative research approach, the authors forensically analyse 54 complaints made by the bidders against the outcomes of the contracts awarded in 2015, which leads to the identification of problematic areas along the critical phases of the procurement process. The authors recommend that the bidders should proactively involve in the identification and reduction of process irregularities.
L. Siddique and B. Hussein in the fourth paper explore the issue of conflicts in agile project management in the Norwegian Software Industry. Using the grounded theory approach, the authors analyse 24 interviews and identify several causes of conflicts (e.g. not getting the right team and clients' lack of knowledge) and their consequences (e.g. loss of motivation and poor decision making). The authors outline strategies for project managers, and discuss the competencies required to handle and resolve conflicts.

In the last paper, W. Ismaeel discusses the introduction of LEED in the Italian building industry. The author identifies that while the shift towards sustainable building process has occurred, there is a lack of green materials and products to satisfy the requirements - the application of LEED in Italian building sector has much room for improvement. The author highlights the need to strike a balance between the preservation of international standardisation while ensuring effective integration of LEED within the regional and local sustainable building practices. Research such as Miller et al. (2015) carried out a study that can address the similar issue.

While the research findings presented in all of the papers in this issue were produced from different countries, they share many similarities with those from past studies conducted elsewhere. This underlines the global relevance of engineering and project management research as well as its translational body of knowledge that can be used to address similar issues being faced worldwide - particularly the roles of regulatory bodies and policy makers in supporting the adoption and diffusion of innovation and best practices.

\section{References}

Miller, D., Doh, J. H., Panuwatwanich, K., and van Oers, N. (2015). The contribution of structural design to green building rating systems: An industry perspective and comparison of life cycle energy considerations. Sustainable Cities and Society, 16, 39-48.

Panuwatwanich, K. and Peansupap, V. (2013). Factors affecting the current diffusion of BIM: a qualitative study of online professional network, Proceedings of the 2013 Creative Construction Conference, Budapest, Hungary, 575-586. 